\title{
$\bullet$ \\ IJCRR \\ Section: Life \\ Secondary Metabolites from the Leaf of Milletia Aboensis Against Streptococcus Mutans Isolated from Carious Lesions
}

Sciences

Sci. Journal Impact Factor: 6.1 (2018)

ICV: 90.90 (2018)

c) (i) (8)

Copyright@IJCRR

\author{
Calister U. Ezeh, Eze E. Ajaegbu, Oluwapelumi O. Komolafe, \\ Adaobi J. Dieke, Flora N. Ezugworie, Adeniran J. Ikuesan, \\ Adaora L. Onuora, Florence O. Nduka, Jennifer N. Ewa-Elechi, \\ Juliet O. Nwigwe, Ese S. Izekor, Nnyeneime U. Bassey, Aduloju A.Tunde
}

Department of Applied Sciences, Faculty of Pure and Applied Sciences and General Studies, Federal College of Dental Technology and Therapy, Trans-Ekulu, Enugu State, Nigeria.

\section{ABSTRACT}

Objectives: The use of traditional medicine as a source of relief from illness is a long-lasting practice. This is because of the possible adverse effects associated with synthetic drugs. The investigation of more plants with antimicrobial activities has been fuelled by the increase of multidrug resistivity of most clinical isolates. Although the leaf of Millettia aboensis has shown antimicrobial potentials against some clinical isolates, there is no report against Streptococcus mutans and detection of the phytoconstituents present.

Methods: Extraction was done according to the maceration process using methanol and further purification via liquid-liquid partitioning. The clinical samples used were cultured anaerobically and aerobically within $72 \mathrm{hr}$ and $48 \mathrm{hr}$ with the blood agar and brain heart infusion broth respectively. The isolates were identified using appropriate tests and methods. The fractions were further analysed for their Phyto-constituents with the help of High pressure liquid chromatography - diode array (HPLC-DAD).

Results: Methanol extraction using $50 \mathrm{~g}$ of plant material produced $12.72 \%$ wet weight, while the fractions using $90 \mathrm{~g}$ of methanol extract produced $30.38 \%$ for water, $20.57 \%$ for hexane, $6.65 \%$ for ethyl acetate, and $4.19 \%$ for butanol as percentage yield. The compounds detected from the fractions of the leaf extract of $M$. aboensis includes septicine - 1, cyclopenol - 2, psammaplin A - 3, 3-phenyl chromen-4-one - 4, hyperin - 5, rikuzenol - 6, hyperoside - 7 and N N-dimethyl tryptophan methyl ester - 8 . There was zero antimicrobial activity recorded at $6.25,12.5,25$ and $50 \mathrm{mg} / \mathrm{ml}$ against Strep. mutans.

Conclusion: The phytoconstituents present in the fractions are promising lead compounds for subsequent investigation in search of new bioactive agents.

Key Words: Millettia aboensis, Antimicrobial, Extract, fractions, Streptococcus mutans.

\section{INTRODUCTION}

Medicinal plants are plants with antimicrobial, antibacterial, anticancer, antitubercular, antimalaria activities ${ }^{1}$. Traditional medicine is the main source of medical care for a great proportion of the population of the developing world ${ }^{2}$. In Africa, indigenous plants play an important role in the treatment of a variety of diseases ${ }^{1}$. As medicinal plants are a suitable alternative for synthetic and chemical drugs; they contain secondary metabolites which have medicinal and physiological potentials $^{3,4}$.

Millettia aboensis are small trees of 30-40 feet high and up to 2 feet in girth, but usually 12 feet high with reddish-brown pubescence on the petioles, branches and fruits. The flowers are purple in erect woody racemes, up to 18 inches long. Almost all the parts of M. aboensis have medicinal properties. The leaf is used by traditional herbalist for general healing, including ulcer and laxatives, while the root is used in treating gastrointestinal disturbances and liver diseases. Also, a decoction of the leaf, stem and root with other plant species is used to cure venereal diseases such as gonorrhoea, syphilis, etc ${ }^{1,5}$. However, the plant parts of M. aboensis are known to be a rich source of steroids, phenolic acids, flavonoids, and alkaloids, hence with medicinal and physiological potentials ${ }^{6}$.Although the leaf of M. aboensis has shown some antimicrobial potential against some clinical isolates,

\section{Corresponding Author:}

Eze E. Ajaegbu, Department of Applied Sciences, Faculty of Pure and Applied Sciences and General Studies, Federal College of Dental Technology and Therapy, Trans-Ekulu, Enugu State, Nigeria; Ph: +2348069744845; Email: ajaegbuee@yahoo.com

ISSN: 2231-2196 (Print)

Received: 28.05 .2020
ISSN: $0975-5241$ (Online)

Revised: 25.07 .2020
Accepted: 09.09.2020
Published: 06.10 .2020 
no report against Streptococcus mutans and detection of the phytoconstituents present. The present study was therefore designed to provide information on the antimicrobial potentials of the extract/fractions and or the secondary metabolites from the leaf of M. Aboensis against $S$. mutans isolated from carious lesions and detect the phytoconstituents using Highpressure liquid chromatography - diode array (HPLC-DAD).

\section{MATERIALS AND METHODS}

\section{Collection, identification and extraction of plant materials}

Fresh leaves of $M$. aboensis were identified and collected from their natural habitat in Amudo-Awka, Anambra State of Nigeria, in January 2015. The plants were identified by Mr. Alfred Ozieko of Bioresources, Development, and Conservation Program (BDCP), Nsukka. Voucher specimens have been deposited in the herbarium section of the Department of Pharmacognosy and Traditional Medicine, Faculty of Pharmaceutical Sciences, Nnamdi Azikiwe University, Awka, with specimen number PCG/474/A/021.The leaves were thoroughly washed using running water and rinsed with distilled water and air-dried to a constant weight at room temperature of $25-27^{\circ} \mathrm{C}$ for 2 weeks, after which it was milled to a fine powder with the aid of a Marlex Exceller grinder.

\section{Solvent extraction}

The extraction process was carried out according to the methods of Ajaegbu et al. ${ }^{7}$ and Onoja et al. ${ }^{8}$ with little modification. Extraction was done according to the maceration process in methanol and further purification via liquid-liquid partitioning. The powdered plant materials of the leaf $(750 \mathrm{~g})$ were extracted exhaustively for two days using the cold maceration method in methanol with intermittent shaking. The maceration process was then repeated for 24 hours in methanol for maximal extraction. The methanol extract was then collected and concentrated almost to dryness under vacuum at $40^{\circ} \mathrm{C}$ using a rotary evaporator. The concentrated methanol leaf extract (MLE)was reconstituted with $200 \mathrm{ml}$ of methanol: water $(2: 8)$ and fractionated successively with hexane, ethyl acetate and butanol and water to give the hexane (MLHF), ethyl acetate (MLEF), butanol (MLBF) and aqueous (MLWF) fractions.

\section{Preparation of test organism}

Clinical isolates of S.mutans that were used for this study were taken from carious lesions of patients that attended the clinic at Federal College of Dental Technology and Therapy, Trans-Ekulu, Enugu. Firstly, all reagents that were to be used for the studies were prepared and stored in a refrigerator. Subsequently, brain heart infusion broth and blood agar were prepared and autoclaved at $121^{\circ} \mathrm{C}$ for 15 mins before antibacterial testing.

\section{Subculturing}

After $48 \mathrm{hr}$ of incubation for aerobic and $72 \mathrm{hr}$ of incubation for anaerobic, the plates were brought out of the incubator. Colonies that developed were respectively subculturing into a freshly prepared blood agar using the streaking method for isolation of pure colonies. The plates were incubated aerobically and anaerobic culture condition. Pure colonies were identified by macroscopic examination of the colony growth on agar plates, morphological characteristics, motility test and other biochemical tests according to standard microbiological procedures ${ }^{9}$. All the organisms that were isolated and identified were stabbed in nutrient agar slant, labelled appropriately and kept in the refrigerator.

\section{Bacterial identification}

Gram stain: Smears of the isolates were prepared and heatfixed on clean grease-free slides ${ }^{10}$. The smears were stained for 1 minute with crystal violet. This was washed out with gentle running tap water. The slides were flooded with dilute gram's iodine solution for 1 minute $^{11}$. This was washed off with water and the smears were decolourized using $95 \%$ alcohol for $30 \mathrm{sec}$. The smears were then counterstained with Safranine solution for $30 \mathrm{sec}$. Finally, the slides were washed with running tap water, air-dried and observed under oil immersion objective lens ${ }^{10}$.

Motility test: Motility test is usually used to differentiate motile organisms from non-motile ones. For this test, the hanging drop technique was employed and the technique was carried out as described by Cheesbrough ${ }^{10}$ and Adeoye et al. ${ }^{12}$. A little Vaseline jelly was rubbed around the cavity of hanging drop slip. A drop of peptone water containing the pure culture was then placed on a coverslip. The hanging drop slide was then placed over the drop of peptone water in such a way that the centre of the depression lies over the drop. The slide was quickly inverted and viewed under the microscope, using the 40X objective lens.

Catalase test: This test is usually used as an aid to differentiate other catalase-positive organisms from catalase negative ${ }^{13}$.A loop full of the pure colony was transferred onto a plane clean glass test tube containing $2 \mathrm{ml}$ of $3 \% \mathrm{v} / \mathrm{v}$ hydrogen peroxide ${ }^{14}$. The reaction was observed immediately for gas production indicated by the production of gas bubbles confirmed the presence of catalase ${ }^{13}$.

Coagulase test: In slide test, a loop full of the isolates was mixed with human plasma at one end of the slide and a loop full of the isolate was mixed with water at the other end to serve as the negative control. The slide was rocked gently for 30 seconds and was allowed to stand. Particles indicating aggregation was used as an indication of coagulase reaction 9

Sugar fermentation test: Each of the isolates were tested for its ability to ferment a given sugar with the product of acid and gas or acid only. Since most bacteria especially 
gram-negative bacteria utilize different sugars as a source of carbon and energy with the production of either acid and gas or acid only. The test is used as an aid in their differentiation. The growth medium used was peptone water and the method used was that described by Kirk et $a l^{15}$. Peptone water was prepared in a conical flask and the indicator, bromocresol purple was added. The mixture was dispensed into test tubes containing Durham tubes. The test tubes with their content were sterilized by autoclaving at $121^{\circ} \mathrm{C}$ for $15 \mathrm{~min} .1 \%$ solution of the sugar was prepared and sterilized separately at $115^{\circ} \mathrm{C}$ for $10 \mathrm{~min}$. This was then aseptically dispensed in 5 $\mathrm{ml}$ aliquots volume into the test tubes containing the peptone water and indicator. The tubes were inoculated with a young culture of the isolates and incubated at $37^{\circ} \mathrm{C}$. Acid and gas production or acid only were observed after about $24 \mathrm{hr}$ of incubation. The control tubes were not incubated ${ }^{15}$. Acid production was indicated by the change of the medium from light green to yellow colour while gas production was indicated by the presence of gas in the Durham tubes ${ }^{16}$.

Indole test: The test is usually used as an aid in the differentiation of gram-negative, bacilli especially those of the Enterobacteriaceae. Tubes of peptone water were inoculated with a young culture of the isolates. The tubes were incubated at $37^{\circ} \mathrm{C}$ for $48 \mathrm{hr}$. About 4 drops of Kovac reagents were added into $1 \mathrm{ml}$ of each of the culture tubes. The positive test was indicated by a red colour that occurs immediately at the upper part of the test tube ${ }^{10}$.

Haemolytic test: Nutrient agar was prepared and allowed to cool at $45^{\circ} \mathrm{C}$ and $5 \%$ sterile sheep blood was added and poured on sterile plates. The plates were then inoculated with the test organism and incubated at $37^{\circ} \mathrm{C}$ for $24 \mathrm{hr}$. After incubation, the plates were checked for zones of haemolysis ${ }^{10}$.

Oxidase test: This test was used to identify the organism that produces the enzyme cytochrome oxidase by oxidizing phenylenediamine. A piece of filter paper was soaked with few drops of oxidase reagent, using a glass rod, an inoculum was picked and was smeared on the filter paper. This was observed for blue-purple colour after $60 \mathrm{sec}^{10}$.

\section{RESULTS}

\section{Extraction}

The yields of the extract and fractions of the extraction process of M. aboensis leaf are shown in Table 1, with MLWF having the highest yield (30.38\%), followed by MLHF (20.57\%) and MLEF (6.65\%) while MLBF gave the lowest yield (4.19\%).

\section{Bacterial Isolate}

From the 36 samples collected, S. mutans were present in 32 samples, 10 from male and 22 from females.
The morphological examination indicates a circular raised cream colony which test positive to gram stain, appears as short rods in shape and is immotile. The test isolate tested negative to catalase, oxidase and indole test. It is coagulasepositive and can ferment mannitol, glucose and lactose.

\section{Antimicrobial evaluation}

The methanol extract and the fractions of the leaf of M. abonesis showed no zone of inhibition against $S$. mutansat varying concentration of 6.25 to $50 \mu \mathrm{g} / \mathrm{ml}$ on the culture plates after $24 \mathrm{~h}$, while the conventional antibiotic showed significant inhibition zone against $S$. mutans even at the lowest concentration of $10 \mu \mathrm{g} / \mathrm{ml}$ as shown in Table 2 .

\section{HPLC-DAD analysis}

HPLC-DAD analysis was suggestive of eight phytoconstituents in the fractions of the methanol extract of the leaf of $M$. aboensis. The structures, Ultraviolet (Uv) spectra and chromatograph of the compounds are shown in Figure 1-4.

\section{DISCUSSION}

The advent of multi-drug resistance in human and animal pathogenic bacteria, as well as undesirable side effects of certain antibiotics, has triggered immense interest in the search of new antimicrobial drugs of plant origin ${ }^{17}$. Nature is a unique source of structures of high phytochemical diversity, many of them possessing interesting biological activities and medicinal properties. Previous studies show that the phytochemical component of M. aboensis is rich in flavonoids, tannis, saponins, and cardiac glycosides ${ }^{18}$. The use of plant extracts with known antimicrobial properties can be of great significance in treatments but several studies have also reported various types of contamination of herbal medicines which include microorganisms and toxins produced by microorganisms, pesticides and toxic heavy metals ${ }^{19}$. Oral diseases are the major problems in public health and one of the chronic diseases that affect humans drastically. The use of plant extract with known antimicrobial activities for the regulation of oral diseases and also an alternative to synthetic antimicrobials can be of great importance in dental caries treatment ${ }^{20}$. Previous preliminary phytochemical screening indicates that $M$. aboensis is a rich source of flavonoids, phenolic acids, tannins, saponins, alkaloids and steroids ${ }^{18}$. The methanol maceration process from $750 \mathrm{~g}$ of plant material of M. aboensis gave a yield of $12.72 \% \mathrm{w} / \mathrm{w}$. From the results reported, MLWF had more yield than all other fractions, while MLBF gave the lowest yield.

S. mutants are predominant in the patient under the age group of $18-25$ years, and this may be as a result of frequent consumption of sugary beverages and food without restrictions ${ }^{21}$. The clinical samples indicate that the females 
are more prone to $S$. mutans than male. This can be attributed to the difference in the eating habits of male and female. The consumption of candy cake chocolate, gum, soft drinks ice cream is higher in female than in male ${ }^{22}$.

The antimicrobial screening of the extract/fractions of the leaf of M. aboensis on the clinical isolates of S.mutans despite their varying concentrations at $6.25 \mathrm{mg} / \mathrm{ml}-50 \mathrm{mg} / \mathrm{ml}$ showed no inhibition. This can also be seen in the report given by Onyegeme-Okerenta and $\mathrm{Okafor}^{23}$, indicating no antimicrobial effect of $M$. aboensis extract against $E$. coli, but showed positive antimicrobial effects on $S$. aureus, $P$. aeruginosa and $K$. pneumoniae at $12.5 \mathrm{mg} / \mathrm{ml}-400 \mathrm{mg} / \mathrm{ml}$ concentrations. The observed result with the methanol extract/fractions may be due to solubility of active compounds in methanol or inhibitors to the antimicrobial component ${ }^{24}$. Okigbo et al and Okigbo \& Igwe ${ }^{25,26}$ reported also inactivity of plant extracts which may be as a result of the age of the plant, type of extracting solvents, the period of harvesting of plant material and extraction method.

The HPLC screening suggested the presence of septicine - 1 in MLHF (Figure 1); cyclopenol - 2, psammaplin A 3, 3,3-phenylchromen-4-one - 4 and hyperin - 5 in MLEF (Figure 2); rikuzenol - 6 and hyperoside - 7 in MLBF (Figure 3); and N,N-dimethyl tryptophan methyl ester in MLWF (Figure 4). Septicine is a toxic amine resulting from bacterial proteolysis which has potential as a cytotoxic (anticancer) agent ${ }^{27}$.Cyclopenol is a naturally occurring 7 -membered 2 , 5-dioxopiperazine alkaloid isolated from the extract of fungus penicillium cyclopium, penicillium sclerotiorum etc. Cyclopenol can be converted into the quinolone viridicatol, by the enzyme cyclopenase present in the conidia. Cyclopenol has phytotoxic and antimicrobial activities ${ }^{28}$.

Psammaplin is a marine natural product which inhibits aminopeptidase $\mathrm{N}$ and suppresses angiogenesis in vitro. Is a phenolic natural product isolated from a marine sponge, which showed potent cytotoxicity against several cancer cell lines ${ }^{29}$. 3-phenylchromen-4-one is an isoflavone. Isoflavones are reported to have a variety of bioprotective effects, including antioxidant, antimutagenic, anticarcinogenic and antiproliferative activities. They protect the body from hormone-related cancers, like breast, endometrial (uterine) and prostatic $30,31,32,33,34$. Hyper in belongs to the class of organic compounds known as flavonoid-3-o-glycosides. It has shown anti-inflammatory, anticarcinogenic and antihistamine properties. It helps in the reduction of depression, heart disease, fatigue, anxiety and cancer ${ }^{35}$.

Rikuzenol is a phenyl ether that was first isolated from cultured lichen mycobionts of Graphis rikuzensis ${ }^{36}$. When screened for its cytotoxicity against murine lymphoma cell line (L5178Y) using the MTT method, it exhibited no activity $^{37}$. Hyperoside also is known as quercetin-3-O-Dgalactoside is a flavonol glycoside present in a variety of vegetables and fruits ${ }^{38,39}$. It has been isolated from various medicinal plants such as Hypericum perforatum ${ }^{40}$, Ligularia fischeri ${ }^{41}$ Crataegus davisii, ${ }^{42}$ Divaricate saposhnikovia ${ }^{43}$, and Hypericum mysorense ${ }^{44}$. Hyperoside is associated with several potent pharmacological activities which include anti-inflammatory, anti-thrombotic, antidiabetic, anti-viral, anti-fungal, hepatoprotective, and antioxidant protective effects ${ }^{45,46,47,48,49}$.N,N-dimethyl tryptophan methyl ester belong to the class of tryptophan esters. Tryptophan esters have shown to bypass the absorptive defect of Hartnup disease in young children ${ }^{50}$, and antitumor properties in various animal models $^{51}$.

\section{CONCLUSION}

From this study, HPLC-DAD techniques revealed the presence of eight compounds and it can be concluded that the antimicrobial screening of the methanol extract/fractions of $M$. aboensis showed no activity against $S$. mutans, but with promising phytoconstituents present, there is need for purification and identification of these compounds present in the extract/fractions which could be exploited for pharmaceutical use.

\section{ACKNOWLEDGEMENT}

The authors are grateful to the Institute for Pharmaceutical Biology and Biotechnology, Heinrich-Heine Universität Düsseldorf for providing the facilities for the HPLC-DAD measurements.

\section{Conflict of interest}

The authors declare no conflict of interest.

Author Contributions: Conceptualization, UCE, EEA and AJD; methodology, UCE, EEA, AJD, FNE and ALO; investigation, UCE, EEA, AJD, FNE, AJI, ALO, FON, JNE, JON, ESI, NUB and AAT; formal analysis, UCE, EEA, AJD, FNE, AJI, ALO, FON, JNE, JON, ESI, NUB and AAT; validation, UCE, EEA, AJD, FNE, and ALO; data curation, EEA AND OOK; writing - original draft preparation, FNE, ALO and OOK; writing - review and editing EEA AND OOK; supervision, EEA; project administration, EEA. All authors have read and agreed to the published version of the manuscript.

Funding: This research received no external funding.

\section{REFERENCES}

1. Phillipson JD. Natural products as drugs. Trans. Royal Soc. Trop. Med.Hyg. 1994;88(suppl 1): S17-9.

2. Ekor M. The growing use of herbal medicines: issues relating to adverse reactions and challenges in monitoring safety. Front Pharmacol. 2013;4(177):1-10. 
3. Bibalani GH, Mosazadeh-Sayadmahaleh F. Recognition and consumption uses and medicinal properties of sour orange (Citrus aurantium) by rural people in the East part of Gilan Province (North Iran). J. Med. Plants Res. 2011;5(7): 1238.

4. Joudi L, Bibalani G. Exploration of medicinal species of Fabaceae, Lamiaceae and Asteraceae families in Ilkhjiregion, Eastern Azerbaijan Province (northwestern Iran). J. Med. Plants Res. 2010;4(11): 1081.

5. Adonu CC, Ugwueze ME, Ozioko CA. Phytochemical analyses of ethanol and water extracts of millettia aboensis, cuscuta reflexa, Daniella oliveri and synclisia scabrida Int J Pharm Bio Sci. 2013;3(2): 64-69.

6. Odhav B, Kandasamy T, Khumalo N, Baijnath H. Screening of African traditional vegetables for their alpha-amylase inhibitory effect. J. Med. Plants Res. 2010;4(14): 1502.

7. Ajaegbu EE, Younoussa L, Danga YSP, Uzochukwu IC, Okoye FBC. Mosquito repellent activity of Spondias mombin L. (Family Anacardiaceae) crude methanol extract and fractions against Aedes aegypti (L.). Indian Journal of Natural Products and Reviews 2016;7(3): 240-244.

8. Onoja SO, Ihejirika GQ, Nwankudu ON, Omeh YN, Ezeja MI. Antidiarrheal and Antioxidant Activities of Methanol Extract of Bryophyllum pinnatum Leaf Harvested from South-Eastern Nigeria in Mice. Journal of Pharmaceutics 2018: 1-6.

9. Cheesbrough M. District Laboratory Practice in Tropical Countries. (Part II). Tropical Health Technology Publishers, Great Britain 2002:1- 157.

10. Cheesbrough M. District Laboratory Practice in Tropical Countries (Part I) Second edition, Cambridge University Press, Cambridge, UK 2005:1-404.

11. Harekrishna J, Tamanna R, Keshab CM, Pradip KD. The Rapid and Easy Method to Detect the Pathogenic Aerobic Bacteria without Staining: A Case Study from Bankura and Its Surrounding Area, West Bengal, India. Sch. Acad. J. Biosci. 2016;4(4A):366-369.

12. Adeoye BK, Obayemi MO, Akinola SA. Isolation, characterization and storage of probiotics associated with the fermentation of Bambara groundnut bran. J Nutr Health Food Eng. 2018;8(6):460-465.

13. Taylor WI, Achanzar D. Catalase Test as an Aid to the Identification of Enterobacteriaceae. Applied Microbiology 1972;24(1): 58-61.

14. Barker FJ, Breach MR. Basic medical laboratory technology, Pitman Medical Publishing Press, London 1976: 158-168.

15. Kirk CJC, Peel RN, Kershe WRJ. Basic Medical Laboratory Technology. Pitman Medical Publishing Press, London 1975: 86-168.

16. Zinnah MA, Bari MR, Islam MT, Hossain MT, Rahman MT, Haque MH, Babu SAM, Ruma RP, Islam MA. Characterization of Escherichia coli isolated from samples of different biological and environmental sources. Bangl. J. Vet. Med. 2007;5(1\&2): 25-32.

17. Masoumian M, Zandi M. Antimicrobial Activity of Some Medicinal Plant Extracts against Multidrug-Resistant Bacteria. Zahedan J Res Med Sci. 2017;19(11): 1-8.

18. Onyegeme-Okerenta BM, Onyeike EN, Esialekpe FO. Effect of ethanol leaf extract of millettia aboensis on selected haematological indices of Wistar albino rats. Global Advanced Research Journal of Medicinal Plants 2013;2(1): 004-011.

19. Talaly P, Talaly P. The importance of using scientific principles in the development of medicinal aspects of plants Acad. Med. 2001;76: 238-247.

20. Palombo EA. Traditional Medicinal Plant Extracts and Natural Products with Activity against Oral Bacteria: Potential Applica- tion in the Prevention and Treatment of Oral Diseases. EvidenceBased Complementary and Alternative Medicine. 2011: 1-15.

21. Poobalan AS, Aucott L, Clarke A, Smith WCS. Diet behaviour among young people in transition to adulthood (18-25 years old), a mixed-method study. Health psychology and Behavioural Medicine. 2014;2(1):909-928.

22. Manippa V, Padulo C, van der Laan L, Brancucci A. Gender Differences in food choice: Effects of superior Temporal Sulcus Stimulation. Frontiers in Human Neurosciences. 2017;11: 597.

23. Onyegeme-Okerenta BM, Okafor UA. Antimicrobial Properties of Ethanol Leaf Extract of Millettia aboensis on Some Selected Clinical Isolates.Universal Journal of Plant Science 2014;2(5):97-101.

24. Enwuru NV, Ogbonnaya SO, Nkemehule F, Enwuru CA, Tolani O. Evaluation of antibacterial activity and acute toxicity of the hydroethanolic extract of stachytarpheta angustifolia (Mill) vahl. Afri. J Biotechnol. 2008;7(11): 1740-1744.

25. Okigbo RN, Mbajaka C, Njoku CO. Antimicrobial potential of (UDA) xylopia aethiopical and ocimum gratissimum on some pathogen of man int J. mol. Med Ad. Sci. Pakistan I 2005;(4): 392-394.

26. Okigbo RN, Igwe M. The antimicrobial effects of piper guineense uziza and phyllanthus amarus obo-benizo or candida albicans and streptococcus faecalis. Acta microbiological f Immunological Hungarica 2007;54(4): 353-366.

27. The Free Dictionary [Internet]. "septicine". Segen's Medical Dictionary, Farlex, Inc., 2011 [cited 27 May. 2020]. Available from: https://medical-dictionary.thefreedictionary.com/septicine

28. Birkinshaw JH, Luckner M, Mohammed YS, Mothes K, Stickings CE. Studies in the BCH of microorganisms. 114. Viridicatum and cyclopenol, metabolites of penicillium viridicatum westling and penicillium cyclopium westling. Biochem. J. 1963;89(2): 196-202.

29. Joong Sup Shim, Hyi-Seung Lee, Jongheon Shin, Ho Jeong Kwon. Psammaplin A, a Marine Natural Product, Inhibits Aminopeptidase $\mathrm{N}$ and Suppresses Angiogenesis in Vitro. Cancer Lett. 2004;203(2): 163-9.

30. Birt DF, Hendrich S, Wang W. Dietary agents in cancer prevention: flavonoids and isoflavonoids. Pharmacology \& Therapeutics 2001;90(2-3):157-177.

31. Miadokova E, Masterova I, Vlckova V, Duhova V, Toth J. Antimutagenic potential of homoisofl avonoids from Muscari racemosum. Journal of Ethnopharmacology 2002;18:381-386.

32. Ryan-Borchers TA, Park JS, Chew BP, McGuire MK, Fournier LR, Beerman KA. Soy isoflavones modulate immune function in healthy postmenopausal women. American Journal of Clinical Nutrition 2006;83:1118-1125.

33. Iwasaki M, Inoue M, Otani T, Sasazuki S, Kurashi N, Miura T, Yamoto S, Tsugane S. Plasma isoflavone level and subsequent risk of breast cancer among Japanese women: A nested casecontrol study from Japan Public Health Center-base prospective study group. Journal of Clinical Oncology 2008;26(10):16771683.

34. Scarpato R, Paganucci L, Bertoli A, Fiore L, Pistelli L, Federico G. Licoflavone $\mathrm{C}$ attenuates the genotoxicity of cancer drugs in human peripheral lymphocytes. Phytotherapy Research 2008;22(12):1650-1654.

35. Razavi SM, Zahri S, Zarrini G, Nazemiyeh H, Mohammadi S. Biological Activity of Quercetin-3-O-Glucoside, a Known Plant Flavonoid. A Russian Journal of Bioorganic Chemistry 2009;35(3): 376-378.

36. Yukiko TAKENAKA, Takao TANAHASHI, Naotaka NAGAKURA, Nobuo HAMADA. Phenyl Ethers from Cultured Lichen Mycobionts of Graphis scriptavar.serpentinaand G. rikuzensis. Chem. Pharm. Bull. 2003;51(7): 794-797. 
37. Mohamed SE, , Mohamed LA, Weaam E,Werner EGM,Attila M, Tibor K, Abdelnasser S, Wenhan L, Zhen L, Peter P. Xanthones and sesquiterpene derivatives from a marine-derived fungus Scopulariopsis sp. Tetrahedron 2016;72(19): 2411-2419.

38. Hosseinimehr SJ, Azadbakht M, Abadi AJ. Protective effect of hawthorn extract against genotoxicity induced by cyclophosphamide in mouse bone marrow cells. Environ Toxicol Pharmacol. 2008;25(1): 51-56.

39. Wu LL, Yang XB, Huang ZM, Liu HZ, Wu GX. In vivo and in vitro antiviral activity of hyperoside extracted from Abelmoschus manihot (L) medik. Acta Pharmacol Sin. 2007;28(3): 404409.

40. Zhou T, Chen B, Fan G, Chai Y, Wu Y. Application of highspeed counter-current chromatography coupled with high-performance liquid chromatography-diode array detection for the preparative isolation and purification of hyperoside from Hypericum perforatum with online purity monitoring. J Chromatography A. 2006;1116(1-2): 97-101.

41. Piao XL, Mi XY, Jang YP, Jang MH, Cho EJ. Determination of hyperoside and 2"-acetylhyperoside from Ligularia fischeri by high performance liquid chromatography. Food Chem. 2011;129(1): 213-216.

42. Sözer U, Donmez AA, Meriçli AH. Constituents from the leaves of Crataegus davisii Browicz. Sci. Pharm.. 2006;74: 203-208.

43. Li L, Gui Y, Wang J, Zhang H, Zong X, Liu CM. Preparative separation of hyperoside of seeds extract of Saposhnikovia divaricata by high performance countercurrent chromatography. J Med Plants Res. 2012;6(5): 884-887.
44. Hariharapura RC, Mahal HS, Srinivasan R, Jagani H, Vijayan P. A pulse radiolysis study of hyperoside isolated from Hypericum mysorense. Radiat Phys Chem.2015;107: 149-159.

45. Huang K, Yang XB, Huang ZM. Research progress in pharmacological activities of hyperoside. Herald Med. 2008;28: 10461048 .

46. Li S, Zhang Z, Cain A, Wang B,Long M, Taylor J. Antifungal activity of camptothecin, trifolin, and hyperoside isolated from Camptotheca acuminate. J Agric Food Chem. 2005;53: 32-37.

47. Makheswari MU, Sudarsanam DD. Interaction of hyperoside and $\beta$-sitosterol with alanine transaminase using molecular docking. Int J Pharma Res Rev. 2013;2: 17-24.

48. Ku SK, Kim TH, Lee S, Kim SM, Bae JS. Antithrombotic and profibrinolytic activities of isorhamnetin-3-Ogalactoside and hyperoside. Food Chem Toxicol. 2013;53: 197-204.

49. Piao MJ, Kang KA, Zhang R, Ko DO, Wang ZH, You HJ, Kim HS, Kim JS, Kang SS, Hyun JW. Hyperoside prevents oxidative damage induced by hydrogen peroxide in lung fibroblast cells via an antioxidant effect. Biochim Biophys Acta 2008;1780(12): 1448-1457.

50. Jonas AJ, Butler IJ. Circumvention of defective neutral amino acidtransport in Hartnup disease using tryptophanethyl ester. J Clin Invest. 1989;84(1):200-204.

51. Oosterkamp HM, Vlasveld LTh, Wanders J, Beijnen JH, Tellingen Ovan, Dubbelman AC, Simonetti GPC, Franklin HR, Vermorken JB, Ten Bokkel Huinink WW. Phase I study of vintriptol, a tryptophan ester of vinblastine. European Journal of Cancer and Clinical Oncology 1991;27(10): 1222-1226. 